\title{
EDITORIAL
}

\section{REVOLUCIÓN 4.0}

La Educación en Ingeniería está llena de profundos desafíos que son referenciados en los diversas organizaciones del orden mundial y nacional, tal como IEEE, ACM, ABET y a nivel nacional ACOFI, donde en general, manifiestan lo quede debería ser el Ingeniero del Siglo XXI, desde allí se pone de manifiesto unas serie de características importantes, que sumada a las competencias del Siglo XXI en relación con el pensamiento crítico, creatividad e innovación, Aprender a aprender, colaboración, habilidades comunicativas, liderazgo, ciudadanías local y global, responsabilidad personal y social, entre otras.

Frente a este desafío que nos demanda la educación de hoy, surge entonces, el siguiente cuestionamiento ¿cuál debe ser la ruta de las facultades de ingeniería para intentar acercarnos a estos requerimientos del siglo XXI? Intentaremos reflexionar sobre este interrogante y plantear algunos lineamientos que pueden ser útiles para seguir en las facultades de Ingenierías, entre los que se destacan los siguientes:

1. Políticas institucionales de innovación educativa

2. Desarrollo curricular pertinente y flexible basado en estándares internacional

3. Laboratorios de innovación educativa.

4. Estrategias de Aprendizaje Activo.

5. Aprendizaje basado en proyectos interdisciplinares basada en la resolución de problemas de ingeniería en el contexto.

Las políticas de innovación educativa de la OECD son un referente importante para que sean adaptados y motiven la reflexión en las instituciones educativas en sus estrategias y formar de implementación, que permitan el estudio, análisis y desarrollo de políticas de innovación educativa en las facultades de ingenierías, enmarcadas por una apuesta generadora de valor que potencie y desarrolle las habilidades que requiere el ingeniero de hoy.

La apuesta hacia un currículo pertinente y flexible que reconozca y comprenda el contexto y las realidades nacionales, pero que también se ajuste al pensamiento global y a los requerimientos del entorno internacional, hoy las apuestas de CDIO, la implementación de propuestas de currículos con los lineamientos de ACM y la IEEE son cada día referente de éxito e impacto en las facultades de ingeniería.

Una apuesta significativa para la transformación educativa en las facultades de ingeniería son los laboratorios de innovación educativa, como eje central donde se implemente las estrategias de un modelo educativo integrador, que tenga como eje central el aprendizaje del estudiante, dinámico, que reconozca los cambios y las transformaciones de las tecnologías educativas en los procesos de formación.

Las implementación de estándares internacionales, también prevé un cambio en modelos educativos, incluyendo estrategias en las aulas, impulsadas por metodologías activas, guiadas por nuevas tendencias en tecnologías educativas y el desarrollo de proyectos de aula interdisciplinares soportado en la realidad de problemas del contexto, fundamentados en un marco de competencias que evidencie el progreso alcanzado por los aprendices.

\section{DANIEL JOSE SALAS ALVAREZ}

MSc. En Informática 